\title{
T cell-mediated oral tolerance is intact in germ-free mice
}

\author{
K. L. W. Walton, ${ }^{\star \dagger}$ J. A. Galanko, \\ R. Balfour Sartor ${ }^{\star \star \S}$ and N. C. Fisher ${ }^{\star \star 9}$ \\ ${ }^{*}$ Department of Medicine, ${ }^{\dagger}$ SPIRE Program, \\ ${ }^{\ddagger}$ Center for Gastrointestinal Biology and Disease, \\ and ${ }^{\S}$ Department of Microbiology and \\ Immunology, University of North Carolina, \\ Chapel Hill, NC, USA
}

\begin{abstract}
Summary
Commensal enteric bacteria stimulate innate immune cells and increase numbers of lamina propria and mesenteric lymph node (MLN) T and B lymphocytes. However, the influence of luminal bacteria on acquired immune function is not understood fully. We investigated the effects of intestinal bacterial colonization on $\mathrm{T}$ cell tolerogenic responses to oral antigen compared to systemic immunization. Lymphocytes specific for ovalbumin-T cell receptor $\left(\mathrm{OVA}-\mathrm{TCR} \mathrm{Tg}^{+}\right.$) were transplanted into germ-free (GF) or specific pathogenfree (SPF) BALB/c mice. Recipient mice were fed OVA or immunized subcutaneously with OVA peptide (323-339) in complete Freund's adjuvant (CFA). Although the efficiency of transfer was less in GF recipients, similar proportions of cells from draining peripheral lymph node (LN) or MLN were proliferating 3-4 days later in vivo in GF and SPF mice. In separate experiments, mice were fed tolerogenic doses of OVA and then challenged with an immunogenic dose of OVA 4 days later. Ten days after immunization, lymphocytes were restimulated with OVA in vitro to assess antigen-specific proliferative responses. At both high and low doses of OVA, cells from both SPF and GF mice fed OVA prior to immunization had decreased proliferation compared to cells from control SPF or GF mice. In addition, secretion of interferon (IFN)$\gamma$ and interleukin (IL)-10 by OVA-TCR Tg lymphocytes was reduced in both SPF and GF mice fed OVA compared to control SPF or GF mice. Unlike previous reports indicating defective humoral responses to oral antigen in GF mice, our results indicate that commensal enteric bacteria do not enhance the induction of acquired, antigen-specific $\mathrm{T}$ cell tolerance to oral OVA.
\end{abstract}

Keywords: commensal bacteria, germ-free mice, mucosal immunity, oral tolerance

\section{Introduction}

The intestinal mucosa is a major interface between an organism and its environment. Resident immune cells encounter continuously a wide variety of antigens, derived from food, commensal enteric flora or ingested pathogens. Thus, the intestinal immune system faces the challenge of maintaining a state of tolerance to self-antigens and non-pathogenic nonself-antigens, while remaining poised for a rapid, protective response to pathogens. Food antigens encountered in the gastrointestinal tract elicit typically a state of antigen-specific systemic hyporesponsiveness, called oral tolerance. Oral tolerance can occur through clonal deletion [1], anergy [2] or the generation of regulatory $\mathrm{T}$ cells $[3,4]$, depending on fac- tors such as antigen dose. Co-stimulatory molecules such as CD86 [5] and CTLA-4 [6], but not CD40 [7,8], are important in the induction of oral tolerance. In addition, regulatory cells producing transforming growth factor (TGF)- $\beta$ $[3,4]$ have been implicated in oral tolerance. There are mixed reports in the literature regarding the importance of interleukin (IL)-10, another cytokine considered widely to be immunoregulatory, in oral tolerance to soluble protein antigens $[3,6,9,10]$. Induction of a potentially regulatory $\mathrm{CD}^{+} /$ $\mathrm{CD} 25^{+}$cell population has also been demonstrated in lowdose oral tolerance models [10,11].

Alterations in the pathway leading to oral tolerance can cause serious consequences, including food hypersensitivity and pathogenic immune responses to the normal intestinal 
microbiota. Indeed, loss of tolerance to commensal enteric bacteria has been demonstrated in inflammatory bowel diseases (IBD) [12-14]. In addition, many rodent models of IBD do not develop disease in a germ-free (GF) setting, but develop colitis rapidly when colonized with specific pathogen-free (SPF) bacteria [15-17] or selected enteric bacterial species [18], and exhibit Th1 responses to commensal enteric bacterial antigens $[17,18]$. Interestingly, a recent study reported reductions in oral tolerance to keyhole limpet haemocyanin, a soluble protein, in patients with IBD [19]. However, the mechanisms underlying tolerance to the commensal microbiota and the loss of tolerance in disease are not understood.

Commensal enteric bacteria also play an integral role in the development of the mucosal immune system. Significant alterations in gut-associated lymphoid tissues (GALT) occur in GF animals, including reduced numbers of intraepithelial lymphocytes (IEL) [20], reduced numbers and size of Peyer's patches (PP) [21,22] and reduced secretion of IgA [23]. These alterations are normalized rapidly upon colonization with non-pathogenic commensal bacteria [2022]. Bacterial antigen-specific $\mathrm{T}$ cells may participate in regulating gut immune responses. For example, bacterial antigen-specific $\mathrm{T}$ regulatory cells that secrete IL-10 in response to caecal bacterial lysates can suppress pathogenic Th1 cell proliferation and prevent colitis in a co-transfer model [24].

The importance of commensal bacteria in GALT development and gut immune responses supports a hypothesis that oral tolerance may be altered in GF mice. Early studies using sheep red blood cells as the antigenic stimulus showed that GF mice had defective antibody responses to oral antigen, which was restored by co-administration of lipopolysaccharide (LPS) [25]. Th1-dependent but not Th2-dependent antibody responses were reduced in GF mice after feeding with ovalbumin (OVA), while both types of responses were reduced in SPF mice [26]. The authors suggested that this was due to decreased numbers of T cells in GF PP [27]. In contrast, other studies have shown suppression of OVA-specific antibodies in the serum of OVA-fed GF mice to a similar degree to the suppression observed in conventionally housed mice, although the duration of oral tolerance was decreased $[28,29]$. Additionally, serum from OVA-fed GF BALB/c mice suppressed OVA-specific delayed-type hypersensitivity responses in recipient mice [30]. Differences among these studies may be due to a variety of factors such as antigens used, doses and feeding regimens and methods of assessing tolerance.

In the current studies, we utilized the adoptive transfer of OVA-specific-T cell receptor (OVA-TCR) $\mathrm{Tg}^{+}$lymphocytes from DO11.10 transgenic mice into syngeneic GF and SPF mice to assess the impact of the absence of intestinal bacterial on oral tolerance at the level of $\mathrm{T}$ cell activation and sensitization. Because different doses of antigen may induce oral tolerance by different cellular mechanisms [1-4,10,29], we used both high- and low-dose feeding regimens. We provide evidence that commensal enteric bacteria are not required for the induction of tolerance to oral antigen in adoptively transferred OVA-TCR $\mathrm{Tg}^{+} \mathrm{T}$ cells.

\section{Materials and methods}

\section{Mice}

DO11.10 (OVA-TCR Tg ${ }^{+}$) breeder mice on a BALB/c background were originally obtained from D. Y. Loh (Washington University School of Medicine, St. Louis, MO, USA) [31]. SPF BALB/c mice were obtained from Harlan Sprague-Dawley (Indianapolis, IN, USA). BALB/c and DO11 10 mice were maintained under SPF conditions at the University of North Carolina animal facility. GF BALB/c mice were maintained in flexible plastic isolators at the Gnotobiotics Animal Facility of the Center for Gastrointestinal Biology and Disease, located at the Laboratory Animal Resources facility of the North Carolina State University College of Veterinary Medicine. The GF status of the mice was monitored by bi-weekly aerobic and anaerobic culture and Gram stain of stools from each isolator. In addition, stools were cultured from mice at the end of each experiment to confirm that the experimental mice remained sterile. Mice were used at 6-16 weeks of age. All experimental procedures were approved by the University of North Carolina and the North Carolina State University Animal Use and Care Committees.

\section{Adoptive transfer and 5,6-carboxy-succinimidyl- fluorescein-ester (CFSE) labelling of donor cells}

Peripheral (axillary and inguinal) and mesenteric lymph nodes from donor DO11.10 $\mathrm{Tg}^{+}$mice were dissected into sterile phosphate-buffered saline (PBS) containing $0 \cdot 1 \%$ bovine serum albumin (BSA) and $1 \%$ gentamicin to help ensure sterility. Single-cell suspensions were made by pressing the tissues through nylon mesh. Lymphocytes were washed in sterile PBS and injected intraperitoneally (i.p.) into recipient SPF and GF BALB/c mice. Intraperitoneal rather than intravenous injections were used due to technical issues related to handling GF mice in isolators. To track the proliferation of donor cells in vivo, donor lymphocytes were labelled with CFSE (Molecular Probes, Eugene, OR, USA), as described previously [32]. Briefly, unseparated D011.10 lymphocytes were resuspended in sterile PBS containing $0 \cdot 1 \%$ BSA and $1 \%$ gentamicin at $10^{7}$ cells $/ \mathrm{ml}$. CFSE was added to a final concentration of $10 \mu \mathrm{M}$ and the cells were incubated at $37^{\circ} \mathrm{C}$ for $10 \mathrm{~min}$. Labelled cells were washed once with sterile PBS containing 0 $1 \%$ BSA and $1 \%$ gentamicin, washed once with sterile PBS and resuspended in PBS for intraperitoneal injection. Lymphocytes (3$8 \times 10^{6}$ ) were injected into each mouse, depending on the experiment. Higher numbers of cells were used in later experiments after determining that OVA-TCR $\mathrm{Tg}^{+}$cell 
transplantation was typically very poor in GF mice given lower cell numbers.

\section{Feeding and immunizations}

For short-term experiments, 1 day after adoptive transfer of CFSE-labelled OVA-TCR $\mathrm{Tg}^{+}$cells, mice were fed $100 \mathrm{mg}$ OVA in $250 \mu \mathrm{l}$ PBS by oral gavage, immunized subcutaneously (s.c.) with OVA p323-339 in complete Freund's adjuvant (CFA) or left untreated. Mice were killed 3 days after OVA treatment. For long-term experiments, mice were divided into fed and control groups. For highdose experiments, 1 day after adoptive transfer of OVATCR $\mathrm{Tg}^{+}$cells, the fed groups of GF and SPF mice were given $100 \mathrm{mg}$ OVA in $250 \mu \mathrm{l}$ PBS by oral gavage, and control mice were given no OVA. For low-dose experiments, the mice were given either sterile drinking water containing $1 \mathrm{mg} / \mathrm{ml}$ or $0.25 \mathrm{mg} / \mathrm{ml}$ OVA or sterile OVA-free drinking water. Mice were thus given OVA continuously for 5 days. In both high- and low-dose experiments, all mice were immunized s.c. with OVA peptide 323-339 in CFA 4 days after the last antigen encounter. In a separate control experiment, four GF and four SPF BALB/c mice that were not injected with OVA-TCR $\mathrm{Tg}^{+}$cells were immunized s.c. with OVA p323-339 in CFA to test for reactivity of endogenous $\mathrm{T}$ cells to the peptide. Mice were necropsied 10 days after immunization.

\section{Monoclonal antibodies (mAbs) and fluorescence activated cell sorter (FACS) analysis}

The clonotypic anti-transgene monoclonal antibody, KJ1-26 [33] was prepared from hybridoma cells. IgG in hybridoma culture supernatants was purified by protein $\mathrm{G}$ chromatography (Pharmacia, Uppsala, Sweden) and was conjugated to FITC or biotin. Anti-CD4-phycoerythrin (PE) (CT-CD4) was purchased from Caltag (San Francisco, CA, USA). AntiCD25-PE (PC61), anti-CD45RB-PE (16A) and streptavidin-PerCP were purchased from BD Pharmingen (San Diego, CA, USA). Cell surface molecules were detected by staining $10^{6}$ viable cells with the antibody conjugates indicated for $20 \mathrm{~min}$ at $4^{\circ} \mathrm{C}$ in PBS containing $0 \cdot 1 \%$ BSA and $0.01 \%$ sodium azide. Stained cells were washed and, as appropriate, cells were incubated with streptavidin-PerCP for an additional $5 \mathrm{~min}$ and then washed. Data were acquired on a FACScan (Becton Dickinson, Mountain View, CA, USA) and analysed with Summit software from Cytomation, Inc. (Ft Collins, CO, USA). A total of 100000 size-gated lymphocytes were counted routinely.

\section{Proliferation assay}

Lymphocytes from the draining lymph node (LN) (axillary) of fed and control mice were cultured at $2 \times 10^{5}$ cells/well in $200 \mu \mathrm{l}$ complete medium with $10 \%$ fetal calf serum (FCS)
(HyClone, Logan, UT, USA), $50 \mu \mathrm{M}$ 2-mercaptoethanol, $10 \mathrm{mg} / \mathrm{ml}$ folate, $2 \mathrm{mM}$ glutamine, $1 \mathrm{mM}$ pyruvate, $0 \cdot 5 \%$ gentamicin and $0.5 \%$ penicillin-streptomycin and the concentrations indicated of OVA p323-339. An aliquot of cells from each mouse was subjected to FACS analysis to determine the number of OVA-TCR $\mathrm{Tg}^{+}$cells that were present in each well. Mice with undetectable or very poor transplantation (less than $0 \cdot 25 \%$ OVA-TCR $\mathrm{Tg}^{+}$cells in the total lymphocyte population) were eliminated from further analysis. Cells were cultured for 3 days, with $1 \mu \mathrm{Ci}$ of $\left[{ }^{3} \mathrm{H}\right]$-thymidine added for the last $18 \mathrm{~h}$ of culture. Cells were harvested onto glass fibre filters and the incorporated radioactivity was counted. The degree of transplantation of OVA-TCR $\mathrm{Tg}^{+}$cells varied from animal to animal as well as across different experiments, and was typically lower in GF recipients (see Results section). To normalize the proliferation data, the counts per minute (cpm) per well were normalized to the number of input OVA-TCR $\mathrm{Tg}^{+}$cells. The percentage of input transgenic cells in the lymphocytes harvested from each mouse was determined by FACS analysis on a separate aliquot of cells on the day of plating. The absolute number of OVA-TCR $\mathrm{Tg}^{+}$cells was calculated by [(\% OVA-TCR $\mathrm{Tg}^{+}$cells/100)/2 $\times 10^{5}$ total cells plated]. Counts per minute above control per $\mathrm{Tg}^{+}$cell was determined by the following equation: cpm/input $\mathrm{Tg}^{+}$ cell $=\left(\mathrm{cpm}_{\text {stimulated }}-\mathrm{cpm}_{\text {unstimulated }}\right) / \#$ input OVA-TCR $\mathrm{Tg}^{+}$ cells.

\section{Analysis of cytokine secretion}

Lymphocytes from the draining $\mathrm{LN}$ of fed and control SPF and GF mice were cultured in the presence or absence of $1 \mu \mathrm{M}$ OVA p323-339 as described above for proliferation assays. Culture supernatants were collected after $72 \mathrm{~h}$ and frozen at -20 degrees until analysis. The concentrations of interferon (IFN)- $\gamma$ and interleukin (IL)-10 in the supernatants were determined by a sandwich enzymelinked immunosorbent assay (ELISA) (BD Pharmingen. San Jose, CA, USA), according to the manufacturer's instructions. The detection limits for both IFN- $\gamma$ and IL10 were $15 \mathrm{pg} / \mathrm{ml}$.

\section{Statistics}

Student's $t$-test was used to compare differences between two means. For analysis of $\mathrm{T}$ cell proliferation experiments, a randomization test was performed. High- and low-dose experiments were analysed as separate groups. For each combination of control versus fed, GF or SPF and in vitro stimulation with OVA $(0 \cdot 01,0 \cdot 10$ and $1 \cdot 0 \mu \mathrm{M})$ a randomization test was performed by enumerating all possible sums of within-experiment ranks for the fed group and comparing it to the actual sum of within-experiment ranks for the fed group found in the data. In all cases, $P$-values $<0.05$ were considered statistically significant. 


\section{Results}

Transplantation of OVA-TCR $\mathrm{Tg}^{+} \mathrm{T}$ cells is less efficient in GF mice

To assess antigen-induced proliferation and tolerance induction, pooled peripheral lymph node (PLN) and mesenteric lymph node (MLN) lymphocytes from OVA-TCR $\mathrm{Tg}^{+} \mathrm{DO} 11 \cdot 10$ donor mice were transferred adoptively by intraperitoneal injection into GF and SPF mice. The efficiency of cell transfer was consistently less in GF than in SPF recipients. In a typical experiment, GF $\mathrm{BALB} / \mathrm{c}$ recipient mice had $1 \cdot 10 \pm 0 \cdot 10 \% \mathrm{CD}^{+} / \mathrm{KJ} 1-26^{+}$cells in the PLN and $1 \cdot 50 \pm 0 \cdot 05 \% \mathrm{CD}^{+} / \mathrm{KJ} 1-26^{+}$cells in the MLN 4 days after cell transfer, compared to $1.46 \pm 0.09 \%$ in the PLN and $2 \cdot 04 \pm 0 \cdot 01 \%$ in the MLN for SPF recipient mice given identical numbers of the same donor cells $(P<0.05$ for GF versus SPF MLN, and $P=0.09$ for PLN by Student's $t$-test, $n=2-3$ for each tissue). Transplantation was not detectable in 20 $30 \%$ of GF mice consistently across all experiments, regardless of whether or not the mice were exposed to antigen subsequent to adoptive transfer of OVA-TCR $\mathrm{Tg}^{+}$cells. Mice with less than $0 \cdot 25 \% \mathrm{CD}^{+} / \mathrm{KJ} 1-26^{+}$cells were dropped from all subsequent analyses. It has been reported that GF mice lack expression of secondary lymphoid chemokine (SLC) in PP [27], so it is possible that naive DO11-10-derived lymphocytes may not traffic appropriately to PP or MLN in GF mice. However, $\mathrm{CD}^{+} / \mathrm{KJ} 1-26^{+}$cells were present typically in roughly similar proportions in the MLN compared to PLN of GF mice. In one experiment, the proportions of $\mathrm{CD}^{+} /$ $\mathrm{KJ} 1-26^{+}$cells were also assessed in the spleen and blood of recipient GF mice. GF mice with undetectable transplantation of $\mathrm{CD} 4^{+} / \mathrm{KJ} 1-26^{+}$cells in the PLN and MLN also had undetectable transplantation in the spleen and blood (data not shown). This indicates that the reduced transplantation observed in the PLN and MLN of GF recipient mice was not likely to be caused by accumulation of adoptively transferred lymphocytes in the spleen or the blood.

OVA-TCR $\mathrm{Tg}^{+} \mathrm{T}$ cells are activated by oral and subcutaneous OVA in GF mice

CFSE-labelled DO11·10 lymphocytes were transferred to GF and SPF mice, which were subsequently fed either $100 \mathrm{mg}$ OVA, immunized s.c. with the antigenic OVA peptide 323 339 (OVA p323-339) emulsified in CFA or left untreated. Cells from the draining axillary PLN (immunized mice) or MLN (fed mice) were assessed by flow cytometry 3 days later. As shown in Fig. 1, CFSE ${ }^{+} / \mathrm{KJ} 1-26^{+}$lymphocytes in the PLN or MLN of GF and SPF recipients did not undergo a significant degree of proliferation in mice that were not exposed to OVA (control mice). Fewer $\mathrm{CFSE}^{+}$cells were detected in the PLN and MLN of GF versus SPF recipients, as described above. However, in both GF and SPF mice immunized s.c. with OVA in CFA, significant proliferation of $\mathrm{KJ} 1-26^{+}$cells

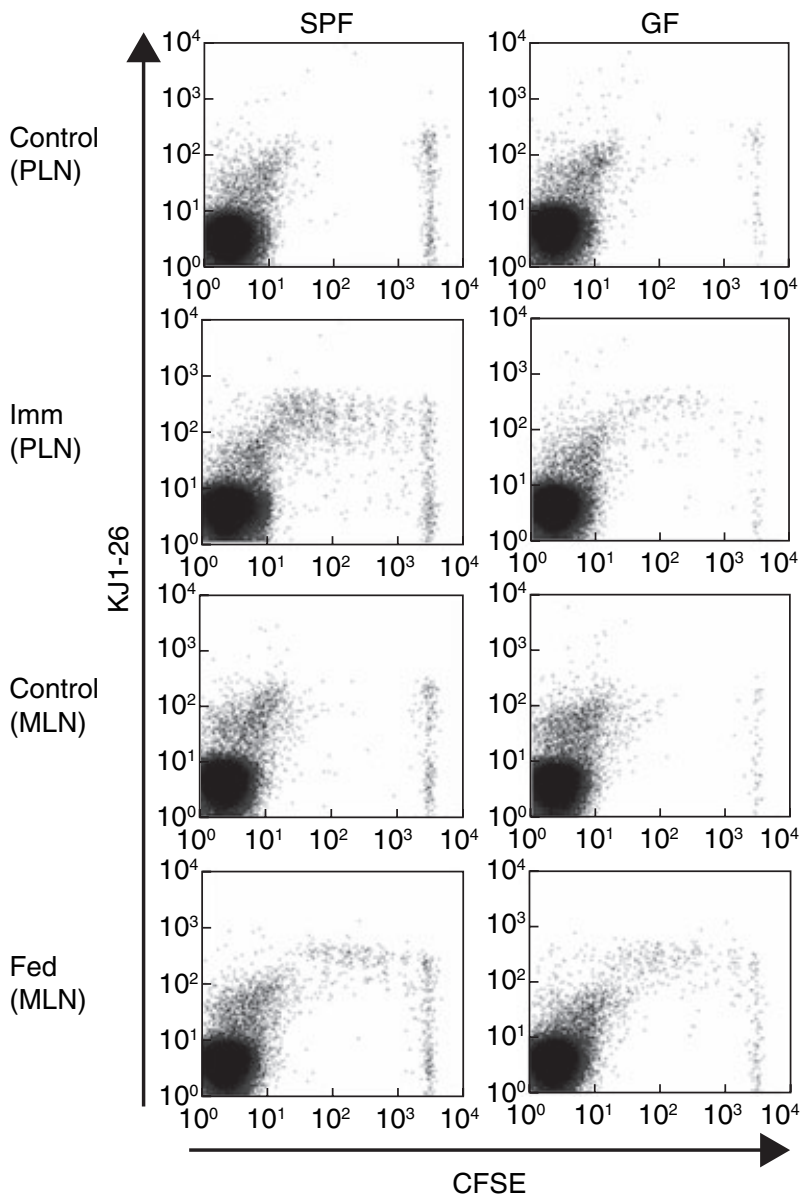

Fig. 1. DO11.10 $\mathrm{Tg}^{+}$cell proliferation in response to antigen in germfree $(\mathrm{GF})$ or specific pathogen-free (SPF) BALB/c mice. SPF or GF $\mathrm{BALB} / \mathrm{c}$ mice injected with 5,6-carboxy-succinimidyl-fluorescein-ester (CFSE)-labelled DO11·10 lymphocytes were given no treatment (Control), immunized subcutaneously with ovalbumin (OVA) p323-339 in complete Freund's adjuvant (CFA) (Imm) or fed 100 mg OVA (Fed). Three days later, draining axillary lymph nodes (PLN) were collected from immunized and control mice, and draining mesenteric LN (MLN) were collected from fed and control mice. Proliferation of OVA-specific cells was assessed by decreased CFSE fluorescence. Each histogram shows data from an individual mouse and is representative of four separate experiments with two to four mice per group in each experiment.

was detected in lymphocytes from the draining PLN, based on decreased intensity of CFSE fluorescence (Fig. 1).

Similar T cell reactivities were seen in MLN cells from OVA-fed GF and SPF mice. In agreement with previous reports [7,32,34], MLN cells from fed SPF mice retained more CFSE fluorescence than cells from the draining PLN of immunized SPF mice (Fig. 1), indicating that less proliferation had occurred in the MLN of fed mice. The average number of cell divisions was increased slightly in the MLN of fed GF mice compared to fed SPF mice (GF, $3 \cdot 4 \pm 0 \cdot 1$ versus SPF, $2 \cdot 8 \pm 0 \cdot 3)$ but this did not achieve statistical significance by 


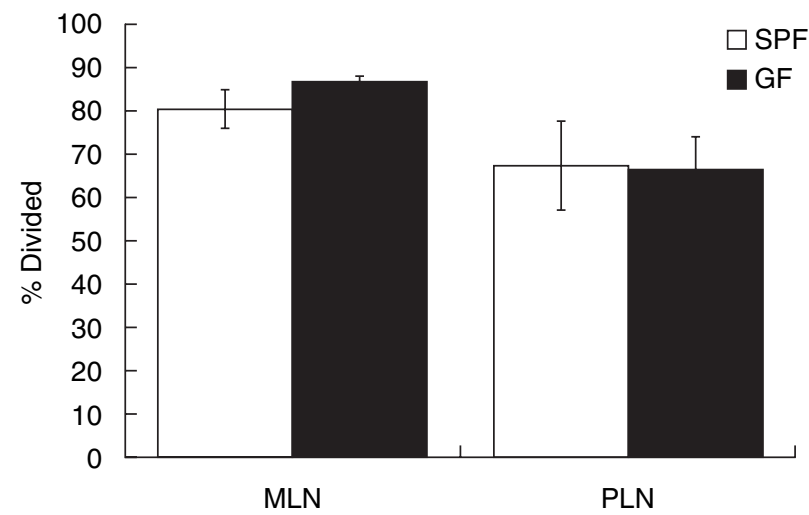

Fig. 2. Proportion of KJ1-26 cells which had divided in germ-free (GF) or specific pathogen-free (SPF) mice. SPF or GF BALB/c were injected with 5,6-carboxy-succinimidyl-fluorescein-ester (CFSE)-labelled

DO11.10 and treated as in Fig. 1. The data shown represent the mean \pm s.d. of $\mathrm{CD} 4^{+} / \mathrm{KJ} 1-26^{+}$cells that had divided at least once, based on loss of CFSE fluorescence, expressed as a percentage of the total number of $\mathrm{CD}^{+} / \mathrm{KJ} 1-26^{+}$cells. The bars labelled MLN (mesenteric lymph nodes) show data from MLN cells from fed mice, while the bars labelled PLN (peripheral lymph nodes) are axillary LN cells from immunized mice. No statistically significant differences were detected between GF and SPF mice in either group (GF versus SPF MLN, $P=0 \cdot 13$ ), $n=4$ for each group.

Student's $t$-test $(P=0 \cdot 16)$. Fewer total cells underwent proliferation in the PLN and MLN of GF mice compared to SPF mice following immunization or feeding, respectively. However, the proportion of cells that had proliferated relative to the total number of $\mathrm{CFSE}^{+} / \mathrm{KJ} 1-26^{+}$cells was again not significantly different in GF and SPF mice in either the fed or the immunized groups (Fig. 2). Taken together, these results indicate that DO11.10 lymphocytes transferred into GF mice are capable of responding to antigen presented by the native antigen-presenting cells in both the PLN and MLN, despite the less efficient transfer of OVA-TCR $\mathrm{Tg}^{+}$cells in GF recipients.

\section{Induction of high-dose oral tolerance to OVA is equal in GF and SPF mice}

We next determined whether any defects were apparent in the induction of oral tolerance in GF mice. GF and SPF cell transfer recipient mice were separated into control groups, which received no OVA, and fed groups, which received $100 \mathrm{mg}$ OVA by gavage. Four days after OVA feeding, all the mice were immunized s.c. with OVA p323-339 in CFA. Ten days later, cells from the draining axillary PLN of all mice were restimulated in vitro with OVA p323-339. Cells from control SPF and GF mice proliferated strongly in response to in vitro restimulation with OVA p323-339 (Fig. 3), showing sensitization of these cells in response to immunization. As expected, cells from SPF mice fed OVA had a significantly

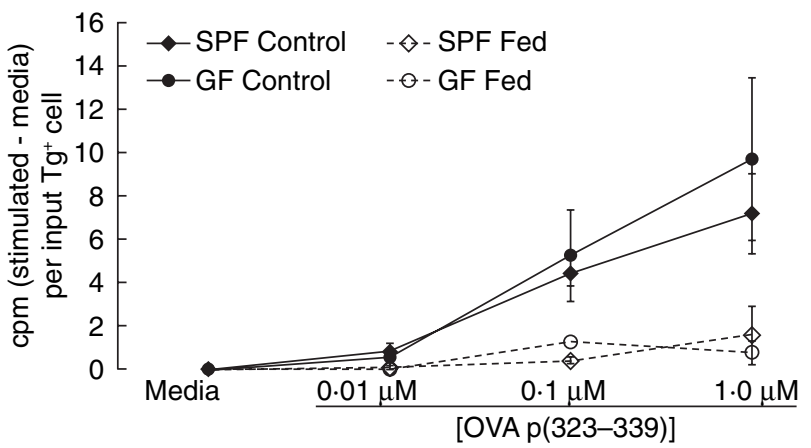

Fig. 3. Oral tolerance is induced in germ-free (GF) mice given a high dose of antigen. Oral tolerance was induced in specific pathogen-free (SPF) and GF BALB/c mice as described in the Methods section. Fed mice were given $100 \mathrm{mg}$ ovalbumin (OVA) by intragastric gavage. Control mice were left untreated. All mice were immunized by subcutaneous injection of OVA p323-339 in complete Freund's adjuvant (CFA); 10 days later, draining axillary LN were collected and cells were restimulated in vitro with ovalbumin peptide at the indicated concentrations. Proliferation was assessed by incorporation of methyl- $\left[{ }^{3} \mathrm{H}\right]$-thymidine. Data are expressed as counts per minute (cpm) (stimulated - media) per input $\mathrm{Tg}^{+}$cell. Data represent the mean \pm s.e.m. of triplicate wells for two to four mice per group and are representative of three similar experiments. Across all three experiments, proliferation was significantly $(P<0.05)$ inhibited in Fed versus Control for SPF at 0.01 and $0 \cdot 1 \mu \mathrm{M}$ OVA p323-339 and for GF at 0.01 $\mu \mathrm{M}$ OVA p323-339. The $P$-value for GF Fed versus Control at $0 \cdot 1 \mu \mathrm{M}$ was $0 \cdot 10$.

diminished proliferation response to 0.01 and $0 \cdot 1 \mu \mathrm{M}$ OVA $(P<0.05)$ (Fig. 3), indicating that these cells had been tolerized by oral OVA. Cells from OVA-fed GF mice showed a similar decrease in proliferative responses (Fig. 3), indicating that oral antigen in GF mice is capable of inducing a similar tolerization of DO11.10 T cells. A statistically significant reduction in DO11.10 cell proliferation in OVA-fed mice relative to control GF mice was not always achieved in a given experiment. This was due largely to the low sample size in individual experiments resulting from exclusion of GF mice with poor $\mathrm{T}$ cell transplantation from the analysis. However, analysis across three experiments determined that GF OVAfed mice showed lower proliferation with $0.01 \mu \mathrm{M}$ OVA p323-339 $(P<0.05)$ and a trend towards lower proliferation with $0 \cdot 1 \mu \mathrm{M}$ OVA p323-339 $(P=0 \cdot 10)$ than the mean proliferation observed with the same concentration of OVA p323-339 in GF control mice.

In a separate control experiment, unmanipulated SPF and GF BALB/c mice were immunized with OVA p323-339 in CFA to test whether endogenous $\mathrm{T}$ cell priming was different in GF mice. Only minimal priming of endogenous OVATCR $\mathrm{Tg}^{+}$cells was observed in both SPF and GF mice. In GF mice, proliferation of lymphocytes in response to in vitro restimulation with $1 \mu \mathrm{M}$ OVA p323-339 was $1 \cdot 8 \pm 0 \cdot 5$-fold over proliferation in unstimulated lymphocytes, compared to $1 \cdot 7 \pm 0 \cdot 6$-fold stimulation over control levels in SPF mice. 


\section{Induction of oral tolerance is intact in GF mice fed low-dose OVA}

Tolerance induced by high doses of oral antigen is mediated primarily by clonal deletion or anergy [1,2], while lower doses of soluble antigens induce tolerance mediated primarily by regulatory $\mathrm{T}$ cells $[3,4,10,11]$. We reasoned that, while oral tolerance is intact in GF mice at high doses of antigen, possible differences might occur in the induction of regulatory $\mathrm{T}$ cells, which would be reflected by defective induction of oral tolerance by lower doses of antigen. Low-dose OVA feeding regimens vary in the literature but are generally less than $5 \mathrm{mg}$ per day for multiple days, with antigen administration either by gavage or via the drinking water [3-5,9-11]. We chose two low doses, $1 \mathrm{mg} / \mathrm{ml}$ or $0.25 \mathrm{mg} / \mathrm{ml}$, given continuously in the drinking water for 5 days. Continuous administration was chosen to minimize the required number of times to open the sterile isolators, in an effort to reduce the likelihood of contamination. GF mice drank slightly higher quantities of OVA-containing water (GF, $4.44 \pm 0.50 \mathrm{ml} /$ day versus $3 \cdot 17 \pm 0 \cdot 24 \mathrm{ml} /$ day for SPF, $P<0 \cdot 01)$. However, both groups drank quantities of OVA ( 4.4 versus $3 \cdot 2 \mathrm{mg} /$ day and $1 \cdot 1$ versus $0.8 \mathrm{mg} /$ day for 5 days for $1 \mathrm{mg} / \mathrm{ml}$ and $0.25 \mathrm{mg} / \mathrm{ml}$ experiments, respectively) which were well within typical ranges used for low-dose tolerance experiments [3-5,9-11]. These mice consumed very similar doses of OVA to mice from a study which demonstrated intact Th2-dependent antibody responses in GF mice despite oral administration of OVA [26]. Results from a representative experiment using $1 \mathrm{mg} / \mathrm{ml}$ OVA for 5 days are shown in Fig. 4. No differences between GF and SPF mice fed OVA were observed in the inhibition of proliferative responses upon in vitro restimulation. Similar inhibition was obtained by feeding $0.25 \mathrm{mg} / \mathrm{ml}$ OVA for 5 days in both GF and SPF mice (data not shown). When the low-dose experiments were analysed together, proliferation in fed groups was significantly reduced relative to control groups for both GF and SPF at all doses of OVA peptide restimulation $(P<0.05$ for fed versus control mice).

\section{IFN- $\boldsymbol{\gamma}$ responses are suppressed in SPF and GF mice after oral tolerance induction}

Exposure to tolerogenic doses of antigen results typically in suppression of cytokine recall responses, in addition to suppression of proliferative recall responses. Therefore, we next measured whether suppression of cytokine secretion by DO11.10 T cells could be observed in cells from control or OVA-fed SPF and GF mice. Lymphocytes were isolated and restimulated as described for the proliferation experiments, and representative samples from four independent experiments were assessed by ELISA for IFN- $\gamma$ and IL-10. Samples from one high-dose experiment and three low-dose experiments were analysed, and the pooled data are shown in Fig. 5. IFN- $\gamma$ secretion was suppressed in OVA-TCR $\mathrm{Tg}^{+}$cells from SPF mice that were fed OVA prior to immunization

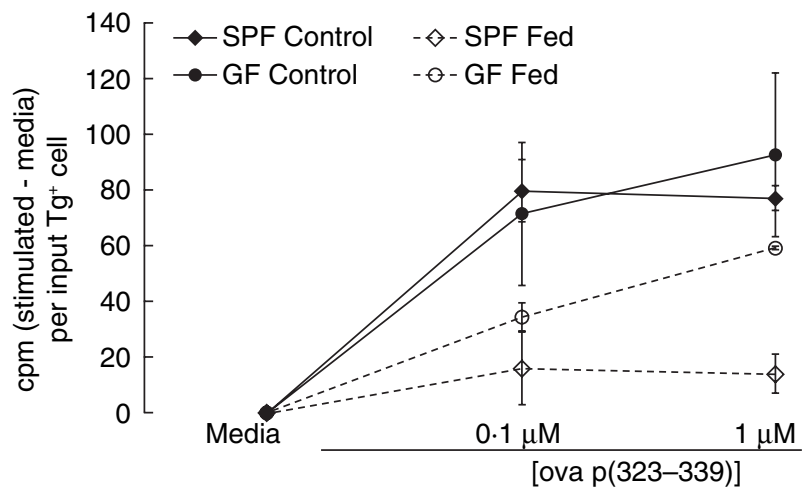

Fig. 4. Oral tolerance is induced in germ-free (GF) mice given a low, continuous dose of antigen. Fed mice were given ovalbumin (OVA) continuously for 5 days in the drinking water at $1 \mathrm{mg} / \mathrm{ml}$. Control mice were given normal drinking water. All mice were immunized by subcutaneous injection of OVA p323-339 in CFA; 10 days later, draining axillary LN were collected and restimulated in vitro with ovalbumin peptide. Proliferation was assessed by incorporation of methyl- $\left[{ }^{3} \mathrm{H}\right]-$ thymidine. Data are expressed as counts per minute (cpm) (stimulated - media) per input $\mathrm{Tg}^{+}$cell. Data represent the mean \pm s.e.m. of triplicate wells for two to four mice per group and are representative of six similar experiments (three experiments using $1 \mathrm{mg} / \mathrm{ml}$ OVA and three experiments using $0 \cdot 25 \mathrm{mg} / \mathrm{ml}$ OVA). Across all low-dose experiments, proliferation in Fed groups was statistically less than in Control groups for both GF and specific pathogen-free (SPF) at all doses of OVA p323$339(P<0 \cdot 05)$.

compared to control SPF mice that were not fed prior to immunization (Fig. 5a). IFN- $\gamma$ secretion was also reduced significantly in OVA-TCR $\mathrm{Tg}^{+}$cells from fed GF mice compared to control GF mice. Interestingly, significantly lower levels of IFN- $\gamma$ were observed in control GF mice compared to control SPF mice $(3 \cdot 8 \pm 1 \cdot 1 \mathrm{pg} / \mathrm{ml}$ per input OVA-TCR $\mathrm{Tg}^{+}$cell for GF controls versus $16.6 \mathrm{pg} / \mathrm{ml}$ per input OVATCR $\mathrm{Tg}^{+}$cell for SPF controls, $\left.P<0 \cdot 05\right)$. IL-10 was low but detectable in SPF control mice (Fig. 5b) and was suppressed to levels near or below the assay detection limit in SPF mice that were fed OVA. In contrast, IL-10 secretion was at or very near the assay detection limit in both control and fed GF mice (Fig. 5b). Neither IFN- $\gamma$ nor IL-10 were detectable in lymphocytes from SPF or GF mice that were not transferred adoptively with OVA-TCR Tg $\mathrm{Tg}^{+}$cells prior to immunization with OVA p323-339 (data not shown).

\section{Discussion}

The current studies tested the requirement for commensal intestinal bacteria in the induction of oral tolerance to a soluble protein antigen. We found that $\mathrm{T}$ cell oral tolerance responses to high- and low-dose OVA were intact in GF mice, contrary to some [25-27] but not all [28-30] previous reports. These conflicting data may be due to several factors, including the model systems used. Our experiments 

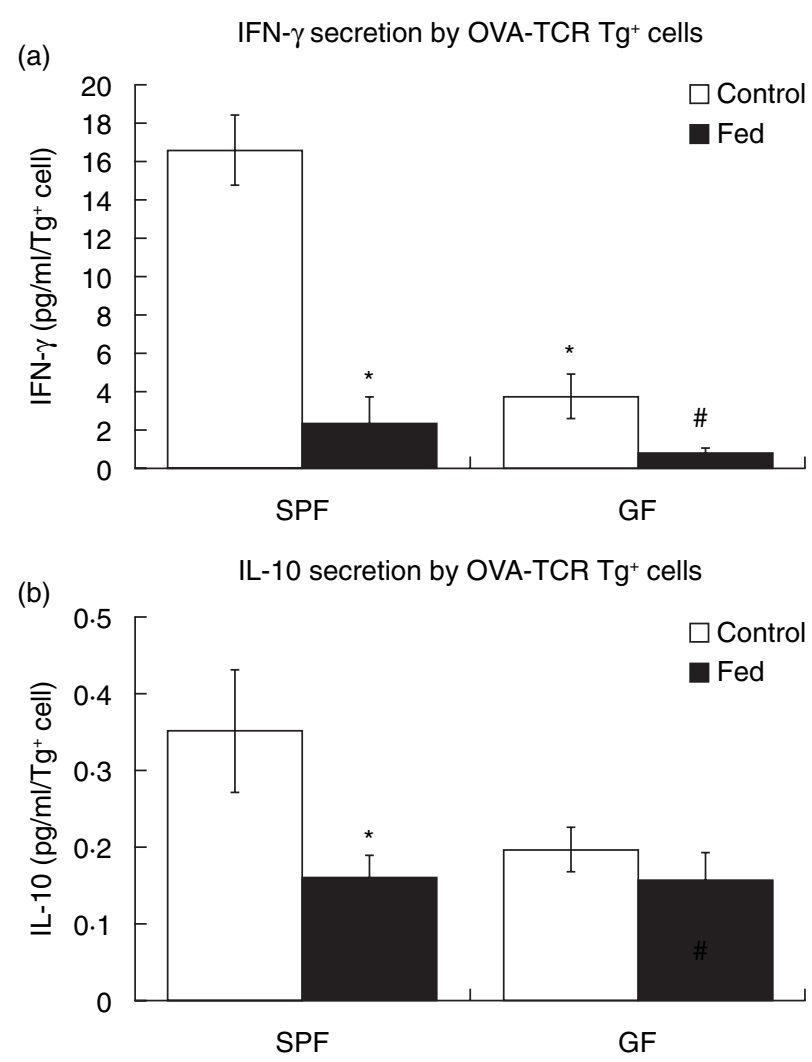

Fig. 5. Secretion of cytokines is reduced in ovalbumin-T cell receptor (OVA-TCR) $\mathrm{Tg}^{+}$cells from germ-free (GF) or specific pathogen-free (SPF) mice fed oral antigen. Lymphocytes were isolated from control or OVA-fed SPF and GF mice and restimulated in vitro with OVA p323339. Supernatants were collected after $72 \mathrm{~h}$ of culture and were analysed by enzyme-linked immunosorbent assay (ELISA) for interferon (IFN)$\gamma(\mathrm{a})$ and interleukin (IL)-10 (b). For each cytokine, the detected concentrations (in $\mathrm{pg} / \mathrm{ml}$ ) were normalized to the number of OVA-TCR $\mathrm{Tg}^{+}$cells in each well to yield $\mathrm{pg} / \mathrm{ml} / \mathrm{OVA}-\mathrm{TCR} \mathrm{Tg}^{+}$cell. Data represent the mean \pm s.e.m. for six to eight mice per group and include representative mice from four independent experiments, including both experiments using both high-dose (one experiment) and low-dose (three experiments) feeding regimens. ${ }^{*} P<0.05$ versus SPF control, $\# P<0 \cdot 05$ versus GF control.

addressed tolerance in a widely used model, in which monoclonal antigen-specific T cells from SPF DO11.10 mice were transferred adoptively into SPF or GF BALB/c mice. In contrast, prior studies have assessed polyclonal oral tolerance in unmanipulated GF mice based on antibody titres following oral antigen administration.

Reports of oral tolerance limiting antibody responses in GF mice included responses to sheep red blood cells and soluble antigens. Wannemuehler et al. [25] showed that GF $\mathrm{BALB} / \mathrm{c}$ and Swiss mice did not develop tolerance in response to orally administered sheep red blood cells, as determined by splenocyte anti-sheep red blood cell antibody responses. The same group showed in a separate report that LPS-resistant $\mathrm{C} 3 \mathrm{H} / \mathrm{HeJ}$ mice did not develop humoral oral tolerance [35]. Another report found that $\mathrm{C} 3 \mathrm{H} / \mathrm{HeJ}$ mice, as well as TLR-4 defective mice on a C57BL6 $\times 129$ background, had elevated allergic responses to peanut allergens co-administered orally with cholera toxin [36]. In addition, antibiotic treatment of TLR-4 wild-type mice recapitulated the elevated IgE levels seen in TLR-4-defective mice [36]. IgE and IgG1, but not IgG2, antibody production was suppressed in GF $\mathrm{C} 3 \mathrm{H} / \mathrm{He}$ mice fed $\beta$-lactoglobulin, although the magnitude of suppression was reduced relative to conventionally housed mice [37]. This study also reported a lack of suppression of splenocyte proliferation in GF $\beta$-lactoglobulin-fed mice [37]. Sudo et al. demonstrated defective oral tolerance in GF BALB/c mice, measured by serum OVA-specific IgE titres in response to challenge with OVA and aluminium hydroxide, which causes an allergic reaction [26]. Interestingly, however, that study also showed suppression of IFN- $\gamma$ secretion by splenocytes isolated from tolerized GF mice [26], which agrees with the suppression of IFN- $\gamma$ recall responses observed in our study. Our data show that adoptively transferred OVA-TCR $\mathrm{Tg}^{+} \mathrm{T}$ cells from an SPF donor mouse are tolerized in a GF setting, demonstrated by suppression of both proliferation and of IFN- $\gamma$ secretion in OVA-TCR $\mathrm{Tg}^{+}$cells. Collectively, these studies suggest that commensal bacteria influence humoral oral tolerance more strongly than cellular oral tolerance. However, $\mathrm{T}$ cell recall responses, as measured by IFN- $\gamma$ secretion, were decreased in GF mice, although proliferative responses were similar to those observed in SPF mice.

In our low-dose oral tolerance experiments, GF mice drank slightly more OVA protein solution than did SPF mice, but no significant differences in induction of tolerance were observed. It is possible that uptake of OVA following feeding is different in GF versus SPF mice. We did not measure directly serum levels of OVA following feeding and so cannot rule out possible differences in uptake of the protein. However, the similar in vivo proliferation observed in GF and SPF mice at 3 days after feeding provides evidence that immunologically active OVA is taken up and presented in both SPF and GF mice.

The role of PP in the induction of oral tolerance has been the subject of conflicting reports. Defective oral tolerance in GF BALB/c mice has been linked to decreased T cell numbers in the PP of GF mice [27]. However, there are conflicting reports on the role of PP in induction of oral tolerance [3840]. Interestingly, the MLN may be a more critical site for oral tolerance induction, as mice lacking both MLN and PP do not show oral tolerance $[39,40]$. Indeed, fed antigen can be detected in antigen-presenting cells in the MLN as well as PP within a few hours of feeding, and antigen-specific T cell proliferation was induced to a similar extent in the MLN, PLN and spleen of normal mice fed OVA compared to mice made PP-deficient by in utero exposure to an anti-IL-7 receptor- $\alpha$ antibody [41]. Subepithelial dendritic cells in areas away from the PP can sample luminal antigens via intra-epithelial dendrites [42]. Our study provides strong evidence 
that both early $\mathrm{T}$ cell proliferative responses and functional tolerance are not impaired in GF mice, which have relatively underdeveloped PP [21-23]. Taken together with the studies discussed above, these data suggest that PP may not be the sole site of oral tolerance induction.

A decrease in the overall efficiency of transplantation of adoptively transferred DO11 10 cells was noted consistently in GF mice in our studies. Reduced trafficking of these naive DO11 10 cells to mucosal tissues, as might be expected based on previous reports of defective SLC expression in the mucosa of GF mice [27] and T cell transfer in the mucosa of reduced-flora SCID mice $[43,44]$, did not appear to underlie the decrease in transplantation, as the cells did not traffic selectively to other lymphoid compartments such as the PLN, spleen or blood. An important point is that the observed decrease in transplantation efficiency did not affect the functional outcome, as long as T cell transplantation was detectable. DO11.10 cells in GF mice were able to be tolerized upon encounter with oral antigen to a similar extent to those cells injected into SPF mice.

Various populations of regulatory $\mathrm{CD} 4^{+} \mathrm{T}$ cells have been described in oral tolerance, including IL-10-producing $\operatorname{Tr} 1$ cells [45], Th3 cells which produce TGF- $\beta[46,47]$ and CD $4^{+} /$ CD25 ${ }^{+}$cells $[10,11]$. The relative importance of each of these cell populations in oral tolerance is currently unknown. Recent studies have pointed to a role for TGF- $\beta$ in continuous-feeding oral tolerance models preferentially at lower doses of antigen [3]. Alterations in TGF- $\beta$-secreting populations of OVA-TCR $\mathrm{Tg}^{+}$cells in GF mice cannot be ruled out in our studies. We did not assess TGF- $\beta$ secretion in this study due to the high baseline levels present in FBS added to the culture media. Some $[3,48]$ but not all $[6,49]$ studies have indicated that IL-10 may be a mediator of oral tolerance. In the current studies, IL-10 was suppressed in cultures of cells from SPF tolerized mice and was secreted in very low levels in cultures of cells from control and tolerized GF mice, regardless of the feeding regimen used to induce oral tolerance. However, these T cells were clearly hypoproliferative in response to in vitro restimulation with antigen, and thus any possible alterations in cytokine secretion did not affect the induction of $\mathrm{T}$ cell hyporesponsiveness. CD25 expression on antigen-specific $\mathrm{T}$ cells with regulatory $\mathrm{T}$ cell activity has been shown previously in models of oral tolerance $[49,50]$. In our model system, induction of CD25 was not observed on OVA-specific $\mathrm{CD} 4^{+}$cells in SPF or GF mice on day 14 after feeding high or low doses of OVA (data not shown), although we did not test further for regulatory activity or for expression of Foxp3, a transcription factor expressed in regulatory $\mathrm{CD} 25^{+} / \mathrm{CD} 4^{+} \mathrm{T}$ cells [51]. It is possible that native $\mathrm{BALB} / \mathrm{c}$ regulatory cells suppressed the OVA-TCR $\mathrm{Tg}^{+}$cells. Indeed, the presence of $\mathrm{CD} 4^{+} / \mathrm{CD} 25^{+}$cells with suppressive capabilities in the MLN of GF Swiss-Webster mice has been reported recently [52].

While GF mice are free of viable bacteria, the standard GF environment still contains trace amounts of LPS and other bacteria-derived products from sterilized food or bedding. Bacteria antigens are presented to gut $\mathrm{T}$ cells by dendritic cells, and LPS or CpG alone are sufficient to activate dendritic cells to block CD25 ${ }^{+}$T cell-mediated suppression [53]. Thus, $\mathrm{T}$ cell responses dependent on bacterial stimulation may be intact in GF mice due to the presence of dietary LPS or CpG. In addition, the OVA-specific T cells used in this study, although naive in terms of OVA exposure, were generated in SPF mice and thus were exposed previously to bacteria. We cannot rule out the possibility that $\mathrm{T}$ cells derived from GF mice might have defective oral tolerance. However, to our knowledge there are currently no TCR transgenic mice that have been made GF, and the adoptive transfer of naive OVA-TCR $\mathrm{Tg}^{+}$cells is therefore a useful and valid approach to assess $\mathrm{T}$ cell responses to oral antigen. Our findings provide strong evidence that oral antigens are taken up and presented effectively to T cells in GF mice, and that naive $\mathrm{T}$ cells are capable of becoming tolerized to oral OVA in the GF environment.

\section{Acknowledgements}

The authors gratefully thank Dr Sue Tonkonogy for use of facilities and equipment and Donna Kronstadt for assistance with germ-free mice. The Gnotobiotic and Biostatistics Core facilities of the Center for Gastrointestinal Biology and Disease are supported by NIH grant P30 DK34987. KLWW is supported by the SPIRE program, funded by the MORE division of the National Institutes of General Medical Sciences grant no. GM00678. This work is also funded by NIH grants RO1 DK53347 (RBS) and A1041579 (NCF).

\section{References}

1 Chen Y, Inobe J, Marks R, Gonnella P, Kuchroo VK, Weiner HL. Peripheral deletion of antigen-reactive $\mathrm{T}$ cells in oral tolerance. Nature 1995; 376:177-80.

2 Van Houten N, Blake SF. Direct measurement of anergy of antigenspecific T cells following oral tolerance induction. J Immunol 1996; 157:1337-41.

3 Faria AM, Maron R, Ficker SM, Slavin AJ, Spahn T, Weiner HL. Oral tolerance induced by continuous feeding: enhanced up-regulation of transforming growth factor-beta/interleukin-10 and suppression of experimental autoimmune encephalomyelitis. J Autoimmun 2003; 20:135-45.

4 Weiner HL. Oral tolerance: immune mechanisms and the generation of Th3-type TGF-beta-secreting regulatory cells. Microbes Infect 2001; 3:947-54.

5 Liu L, Kuchroo VK, Weiner HL. B7.2 (CD86) but not B7.1 (CD80) costimulation is required for the induction of low dose oral tolerance. J Immunol 1999; 163:2284-90.

6 Fowler S, Powrie F. CTLA-4 expression on antigen-specific cells but not IL-10 secretion is required for oral tolerance. Eur J Immunol 2002; 32:2997-3006.

7 Sun J, Van Houten N. CD40 stimulation in vivo does not inhibit $\mathrm{CD}^{+} \mathrm{T}$ cell tolerance to soluble antigens. Immunol Lett 2002; 84:125-32. 
8 Chung Y, Ko SY, Ko HJ, Kang CY. Split peripheral tolerance: CD40 ligation blocks tolerance induction for CD8 $\mathrm{T}$ cells but not for CD4 $\mathrm{T}$ cells in response to intestinal antigens. Eur J Immunol 2005; 35:1381-90.

9 Marth T, Ring S, Schulte D et al. Antigen-induced mucosal T cell activation is followed by Th1 T cell suppression in continuously fed ovalbumin TCR-transgenic mice. Eur J Immunol 2000; 30:347886.

10 Zhang X, Izikson L, Liu L, Weiner HL. Activation of CD25(+) $\mathrm{CD} 4(+)$ regulatory $\mathrm{T}$ cells by oral antigen administration. J Immunol 2001; 167:4245-53.

11 Thorstenson KM, Khoruts A. Generation of anergic and potentially immunoregulatory $\mathrm{CD} 25^{+} \mathrm{CD} 4 \mathrm{~T}$ cells in vivo after induction of peripheral tolerance with intravenous or oral antigen. J Immunol 2001; 167:188-95.

12 Macpherson A, Khoo UY, Forgacs I, Philpott-Howard J, Bjarnason I. Mucosal antibodies in inflammatory bowel disease are directed against intestinal bacteria. Gut 1996; 38:365-75.

13 Duchmann R, Kaiser I, Hermann E, Mayet W, Ewe K, Meyer zum Buschenfelde $\mathrm{KH}$. Tolerance exists towards resident intestinal flora but is broken in active inflammatory bowel disease (IBD). Clin Exp Immunol 1995; 102:448-55.

14 Duchmann R, May E, Heike M, Knolle P, Neurath M, Meyer zum Buschenfelde KH. T cell specificity and cross reactivity towards enterobacteria, bacteroides, bifidobacterium, and antigens from resident intestinal flora in humans. Gut 1999; 44:812-8.

15 Schultz M, Tonkonogy SL, Sellon RK et al. IL-2-deficient mice raised under germfree conditions develop delayed mild focal intestinal inflammation. Am J Physiol 1999; 276:G1461-72.

16 Sellon RK, Tonkonogy S, Schultz M et al. Resident enteric bacteria are necessary for development of spontaneous colitis and immune system activation in interleukin-10-deficient mice. Infect Immun 1998; 66:5224-31.

17 Veltkamp C, Tonkonogy SL, De Jong YP et al. Continuous stimulation by normal luminal bacteria is essential for the development and perpetuation of colitis in $\mathrm{Tg}$ (epsilon26) mice. Gastroenterology 2001; 120:900-13.

18 Kim SC, Tonkonogy SL, Albright CA et al. Variable phenotypes of enterocolitis in interleukin 10-deficient mice monoassociated with two different commensal bacteria. Gastroenterology 2005; 128:891-906.

19 Kraus TA, Toy L, Chan L, Childs J, Mayer L. Failure to induce oral tolerance to a soluble protein in patients with inflammatory bowel disease. Gastroenterology 2004; 126:1771-8.

20 Umesaki Y, Setoyama H, Matsumoto S, Okada Y. Expansion of alpha beta T-cell receptor-bearing intestinal intraepithelial lymphocytes after microbial colonization in germ-free mice and its independence from thymus. Immunology 1993; 79:32-7.

21 Shroff KE, Cebra JJ. Development of mucosal humoral immune responses in germ-free (GF) mice. Adv Exp Med Biol 1995; 371A:441-6.

22 Pollard M, Sharon N. Responses of the Peyer's patches in germ-free mice to antigenic stimulation. Infect Immun 1970; 2:96-100.

23 Talham GL, Jiang HQ, Bos NA, Cebra JJ. Segmented filamentous bacteria are potent stimuli of a physiologically normal state of the murine gut mucosal immune system. Infect Immun 1999; 67:1992-2000.

24 Cong Y, Weaver CT, Lazenby A, Elson CO. Bacterial-reactive T regulatory cells inhibit pathogenic immune responses to the enteric flora. J Immunol 2002; 169:6112-9.
25 Wannemuehler MJ, Kiyono H, Babb JL, Michalek SM, McGhee JR. Lipopolysaccharide (LPS) regulation of the immune response: LPS converts germfree mice to sensitivity to oral tolerance induction. J Immunol 1982; 129:959-65.

26 Sudo N, Sawamura S, Tanaka K, Aiba Y, Kubo C, Koga Y. The requirement of intestinal bacterial flora for the development of an IgE production system fully susceptible to oral tolerance induction. J Immunol 1997; 159:1739-45.

27 Maeda Y, Noda S, Tanaka K et al. The failure of oral tolerance induction is functionally coupled to the absence of T cells in Peyer's patches under germfree conditions. Immunobiology 2001; 204:442-57.

28 Moreau MC, Corthier G. Effect of the gastrointestinal microflora on induction and maintenance of oral tolerance to ovalbumin in C3H/HeJ mice. Infect Immun 1988; 56:2766-8.

29 Moreau MC, Gaboriau-Routhiau V. The absence of gut flora, the doses of antigen ingested and aging affect the long-term peripheral tolerance induced by ovalbumin feeding in mice. Res Immunol 1996; 147:49-59.

30 Furrie E, Turner MW, Strobel S. Failure of SCID mice to generate an oral tolerogen after a feed of ovalbumin: a role for a functioning gut-associated lymphoid system. Immunology 1994; 83:562-7.

31 Murphy KM, Heimberger AB, Loh DY. Induction by antigen of intrathymic apoptosis of $\mathrm{CD} 4^{+} \mathrm{CD} 8^{+} \mathrm{TCR}^{\text {lo }}$ thymocytes in vivo. Science 1990; 250:1720-3.

32 Sun J, Dirden-Kramer B, Ito K, Ernst PB, Van Houten N. Antigenspecific $\mathrm{T}$ cell activation and proliferation during oral tolerance induction. J Immunol 1999; 162:5868-75.

33 Haskins K, Kubo R, White J, Pigeon M, Kappler J, Marrack P. The major histocompatibility complex-restricted antigen receptor on $\mathrm{T}$ cells. I. Isolation with a monoclonal antibody. J Exp Med 1983; 157:1149-69.

34 Smith KM, Davidson JM, Garside P. T-cell activation occurs simultaneously in local and peripheral lymphoid tissue following oral administration of a range of doses of immunogenic or tolerogenic antigen although tolerized $\mathrm{T}$ cells display a defect in cell division. Immunology 2002; 106:144-58.

35 Kiyono H, McGhee JR, Wannemuehler MJ, Michalek SM. Lack of oral tolerance in C3H/HeJ mice. J Exp Med 1982; 155:605-10.

36 Bashir ME, Louie S, Shi HN, Nagler-Anderson C. Toll-like receptor 4 signaling by intestinal microbes influences susceptibility to food allergy. J Immunol 2004; 172:6978-87.

37 Prioult G, Fliss I, Pecquet S. Effect of probiotic bacteria on induction and maintenance of oral tolerance to betalactoglobulin in gnotobiotic mice. Clin Diagn Lab Immunol 2003; 10:787-92.

38 Fujihashi K, Dohi T, Rennert PD et al. Peyer's patches are required for oral tolerance to proteins. Proc Natl Acad Sci USA 2001; 98:3310-5.

39 Spahn TW, Fontana A, Faria AM et al. Induction of oral tolerance to cellular immune responses in the absence of Peyer's patches. Eur J Immunol 2001; 31:1278-87.

40 Spahn TW, Weiner HL, Rennert PD et al. Mesenteric lymph nodes are critical for the induction of high-dose oral tolerance in the absence of Peyer's patches. Eur J Immunol 2002; 32:1109-13.

41 Kunkel D, Kirchhoff D, Nishikawa S, Radbruch A, Scheffold A. Visualization of peptide presentation following oral application of antigen in normal and Peyer's patches-deficient mice. Eur J Immunol 2003; 33:1292-301. 
42 Rescigno M, Urbano M, Valzasina B et al. Dendritic cells express tight junction proteins and penetrate gut epithelial monolayers to sample bacteria. Nat Immunol 2001; 2:361-7.

43 Aranda R, Sydora BC, McAllister PL et al. Analysis of intestinal lymphocytes in mouse colitis mediated by transfer of $\mathrm{CD}^{+}, \mathrm{CD} 45 \mathrm{RB}^{\text {high }}$ T cells to SCID recipients. J Immunol 1997; 158:3464-73.

44 Camerini V, Sydora BC, Aranda R et al. Generation of intestinal mucosal lymphocytes in SCID mice reconstituted with mature, thymus-derived T cells. J Immunol 1998; 160:2608-18.

45 Groux H, O'Garra A, Bigler M et al. A CD4 ${ }^{+}$T-cell subset inhibits antigen-specific T-cell responses and prevents colitis. Nature 1997; 389:737-42.

46 Chen Y, Inobe J, Kuchroo VK, Baron JL, Janeway CA Jr, Weiner HL. Oral tolerance in myelin basic protein T-cell receptor transgenic mice: suppression of autoimmune encephalomyelitis and dose-dependent induction of regulatory cells. Proc Natl Acad Sci USA 1996; 93:388-91.

47 Fukaura H, Kent SC, Pietrusewicz MJ, Khoury SJ, Weiner HL, Hafler DA. Induction of circulating myelin basic protein and proteolipid protein-specific transforming growth factor-betalsecreting Th3 $\mathrm{T}$ cells by oral administration of myelin in multiple sclerosis patients. J Clin Invest 1996; 98:70-7.
48 Tsuji NM, Mizumachi K, Kurisaki J. Interleukin-10-secreting Peyer's patch cells are responsible for active suppression in lowdose oral tolerance. Immunology 2001; 103:458-64.

49 Omata N, Ohshima Y, Yasutomi M, Yamada A, Karasuyama H, Mayumi M. Ovalbumin-specific IgE modulates ovalbuminspecific T-cell response after repetitive oral antigen administration. J Allergy Clin Immunol 2005; 115:822-7.

50 Hauet-Broere F, Unger WW, Garssen J, Hoijer MA, Kraal G, Samsom JN. Functional CD25 $5^{-}$and $\mathrm{CD} 25^{+}$mucosal regulatory $\mathrm{T}$ cells are induced in gut-draining lymphoid tissue within $48 \mathrm{~h}$ after oral antigen application. Eur J Immunol 2003; 33:280110 .

51 Sakaguchi S. Naturally arising Foxp3-expressing $\mathrm{CD} 25^{+} \mathrm{CD} 4^{+}$regulatory $\mathrm{T}$ cells in immunological tolerance to self and non-self. Nat Immunol 2005; 6:345-52.

52 Gad M, Pedersen AE, Kristensen NN, Claesson MH. Demonstration of strong enterobacterial reactivity of $\mathrm{CD} 4^{+} \mathrm{CD} 25^{-} \mathrm{T}$ cells from conventional and germ-free mice which is counter-regulated by CD $4^{+} \mathrm{CD} 25^{+} \mathrm{T}$ cells. Eur J Immunol 2004; 34:695-704.

53 Pasare C, Medzhitov R. Toll pathway-dependent blockade of $\mathrm{CD} 4^{+} \mathrm{CD} 25^{+} \mathrm{T}$ cell-mediated suppression by dendritic cells. Science 2003; 299:1033-6. 